\title{
əThe Impact of Initial Snow Conditions on the Numerical Weather Simulation of a Northern Rockies Atmospheric River
}

\author{
William Rudisill, ${ }^{\mathrm{a}}$ Alejandro Flores, ${ }^{\mathrm{a}}$ AND JAmes MCNAmara ${ }^{\mathrm{a}}$ \\ ${ }^{a}$ Boise State University, Boise, Idaho
}

(Manuscript received 28 January 2020, in final form 4 September 2020)

\begin{abstract}
Snow's thermal and radiative properties strongly impact the land surface energy balance and thus the atmosphere above it. Land surface snow information is poorly known in mountainous regions. Few studies have examined the impact of initial land surface snow conditions in high-resolution, convection-permitting numerical weather prediction models during the midlatitude cool season. The extent to which land surface snow influences atmospheric energy transport and subsequent surface meteorological states is tested using a high-resolution $(1 \mathrm{~km})$ configuration of the Weather Research and Forecasting (WRF) Model, for both calm conditions and weather characteristic of a warm late March atmospheric river. A set of synthetic but realistic snow states are used as initial conditions for the model runs and the resulting differences are compared. We find that the presence (absence) of snow decreases (increases) 2-m air temperatures by as much as $4 \mathrm{~K}$ during both periods, and that the atmosphere responds to snow perturbations through advection of moist static energy from neighboring regions. Snow mass and snow-covered area are both important variables that influence 2-m air temperature. Finally, the meteorological states produced from the WRF experiments are used to force an offline hydrologic model, demonstrating that snowmelt rates can increase/decrease by factor of 2 depending on the initial snow conditions used in the parent weather model. We propose that more realistic representations of land surface snow properties in mesoscale models may be a source of hydrometeorological predictability
\end{abstract}

KEYWORDS: Atmosphere-land interaction; Energy budget/balance; Snow; Model initialization; Mountain meteorology

\section{Introduction}

Seasonal snowpacks are a unique and variable part of the hydrologic cycle. Snow has unique properties, including a high latent heat of melting and a high albedo. The unique thermal and radiative properties of snow can act to alter the atmosphere above it. A variety of studies have empirically quantified snow's cooling effects on surface air temperatures (Ellis and Leathers 1999; Baker et al. 1992; Mote 2008). Surface snow anomalies drive can drive local- and regional-scale wind circulations (Schlögl et al. 2018; Segal et al. 1991; Letcher and Minder 2018), and these in turn impact the lateral advection of heat, moisture, and momentum. Cohen (1994) provides a review of the mechanisms through which snow influences weather and climate. Other studies have documented seasonal snow cover's impacts on storm track dynamics (Sobolowski et al. 2010) and monsoonal circulations (Bamzai and Shukla 1999).

Despite the well-known mechanisms through which snow influences the atmosphere, relatively little research has considered the impact of initial land surface snow conditions in the context of numerical weather prediction or coupled landatmosphere modeling. In this study, we develop a suite of numerical experiments to examine how initial land surface snow conditions [both the snow water equivalent (SWE) and snow-covered area (SCA)] control subsequent land surface

\footnotetext{
๑ Denotes content that is immediately available upon publication as open access.
}

Corresponding author: William Rudisill, williamrudisill@ u.boisestate.edu forcings during both ambient conditions and weather consistent with an atmospheric river (AR).

Atmospheric rivers are long, thin corridors of enhanced water vapor transport that form in the warm sector of extratropical cyclones (Neiman et al. 2008). They are common midlatitude weather features that exert strong controls on annual water budgets in the coastal and intermountain western United States and northern Rockies (Rutz et al. 2015). Winter ARs tend to increase watershed SWE storage, whereas spring ARs tend to decrease SWE storage (Neiman et al. 2008). During the latter, the turbulent exchanges of sensible heat $(\mathrm{SH})$ and latent heat (LH) can melt large volumes of snow (Marks et al. 1998) and can lead to river flooding (Ralph et al. 2006; Neiman et al. 2011).

To answer these questions, we employ a 1-km spatial resolution configuration of the Weather Research and Forecasting (WRF; Skamarock et al. 2008) coupled land-atmosphere model to simulate an event that occurred in March of 1998. We force the model with Climate Forecast System Reanalysis (CFSR; Saha et al. 2010) atmospheric boundary conditions. In the absence of high-quality observational snow information and estimates of uncertainty, we initialize the land surface model with a suite of snow conditions from a regional climate run of the same region (Flores et al. 2016) that reflect a range of realistic snow states.

We apply a tropospheric energy budget framework following Letcher and Minder (2015) and Porter et al. (2011) to quantify the lateral advection of energy between grid cells in response to snow perturbations. Finally, we apply the meteorological forcings produced by the coupled WRF experiments to run an "offline" (i.e., no communication from the land surface back to the atmosphere) snowmelt model, analogous to the setups used in some operational practices (Havens et al. 2019), where meteorological outputs from a weather forecast are used to run an independent 


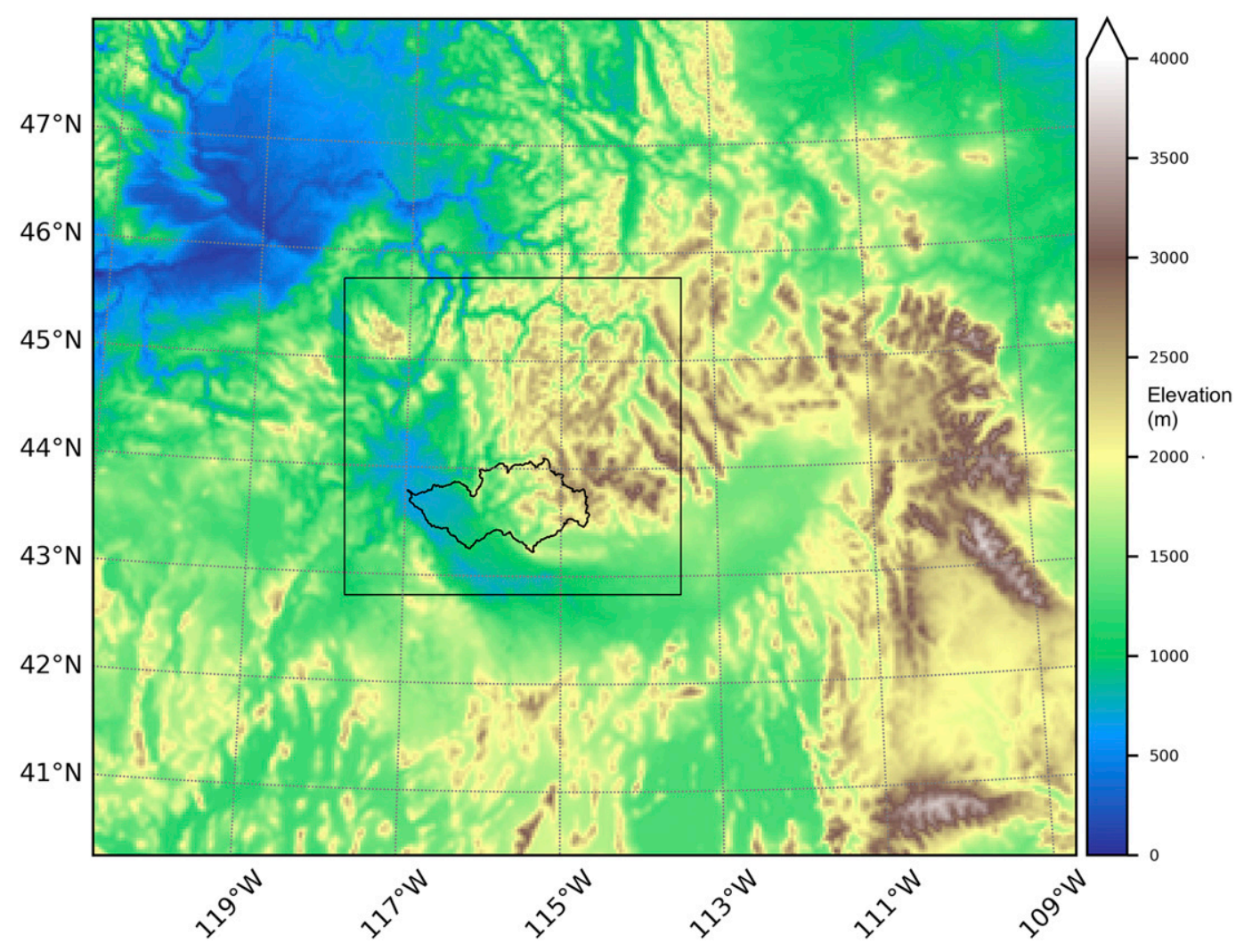

FIG. 1. The WRF modeling domains. The two nested domains have a 3-km (d01) and a 1-km (d02) horizontal grid spacing, respectively. The black outline shows the Boise River basin.

snowmelt model. This experimental framework also serves as a convenient test of land-atmosphere interaction. If the initial snow conditions have no influence on the subsequent meteorological forcings, then the land surface states recorded in the offline models will be identical to each other.

\section{Background information}

\section{a. Study area}

The northern Rockies of central Idaho are characterized by steep and rugged topography. The large gradient in topography between the low-elevation Snake River plain and the Boise, Sawtooth, and Salmon Mountain ranges to the north create large climactic gradients in precipitation and temperature. Our research interest is motivated by a desire to better understand watershed hydrologic responses. Consequently, we restrict our analysis to the Boise River watershed located approximately in the center of the inner $(1 \mathrm{~km})$ model grid (Fig. 1). The watershed has an approximately east-west trend, with mountain peaks upward of $2500 \mathrm{~m}$. Upwind topographic barriers influence moisture delivery to this inland region. The major moisture corridors are through topographic low points in the Sierras and the Columbia River gorge (Alexander et al. 2015). The Boise River basin is characterized by evergreen forests at higher elevations and grass/shrubland in the mid- to low elevations.

\section{b. The March 1998 atmospheric river event}

The AR case study was identified by the authors using commonly accepted identification parameters (Guan and Waliser 2015) computed using CFSR (Saha et al. 2010). Neiman et al. (2008) independently identified the same event from remotely sensed integrated water vapor (IWV) retrievals. The AR had greater than $3 \mathrm{~cm}$ of IWV during both the afternoon and evening pass of the Special Sensor Microwave Imager Sounder (SSM/I) satellite. The storm was able to track inland and precipitate in the northern Rockies in central Idaho. The National Weather Service (NWS) radiosonde located at the Boise Airport (located in the southwest corner of the watershed) recorded $1.4 \mathrm{~cm}$ of total column precipitable water and wind speeds of $28 \mathrm{~m} \mathrm{~s}^{-1}$ at $500 \mathrm{hPa}$ of height at $0000 \mathrm{UTC}$ 28 March 1998 (soundings retrieved from http://weather.uwyo.edu/ upperair/sounding.html). This is not an uncommon type of weather event, as approximately one-fifth of cool season precipitation in this region is attributable to cool-season AR events (Rutz et al. 2015).

\section{Methods}

\section{a. WRF Model description and experimental setup}

We use the advanced research version 3.8.1 of the WRF Model (Skamarock et al. 2008). WRF is a fully coupled (land 
and atmosphere) atmospheric model used for both for research and operational forecasting. We use two nested model domains: an outer grid with a $3-\mathrm{km}$ spatial resolution and an inner, 1-km spatial resolution domain. The convective parameterizations are turned off, given that the inner grid dimension is less than the $4 \mathrm{~km}$ considered necessary to resolve convection (Weisman et al. 1997; Prein et al. 2015). We use the Monin-Obukhov similarity theory surface layer scheme, the Community Atmosphere Model shortwave and longwave radiation schemes, the Mellor-YamadaJanjić TKE planetary boundary layer scheme, Thompson microphysics, and the Noah-MP land surface model (Table 1).

The Noah-MP land surface model (Niu et al. 2011) uses a three-layer mass and energy balance snow model that accounts for melt, refreeze, and liquid water storage within the snowpack. The shortwave radiation calculation employs a two-stream approximation modeling both reflection from the surface and absorption by the vegetation canopy. Longwave radiation and turbulent exchanges are calculated separately for ground and the canopy layer. SCA is determined by a monotonic function of snow depth, density, and a "melt factor" exponent. Our configuration of Noah-MP uses the CLASS scheme to compute snow albedo age decay (Verseghy 1991). The cell-wide surface albedo is computed as the area weighted average of snow surface, bare ground, and vegetation albedo. Niu et al. (2011) provides a more complete description of the land surface model. Noah-MP represents a marked improvement over the previous Noah model in terms of representing snow processes, particularly due to the improved representation of vegetation and canopy processes.

\section{b. Coupled modeling experimental setup}

We performed a total of five WRF simulations for the March 1998 AR event. For the baseline simulation, we use the standard CFSR land surface initial conditions and snow state. The other simulations are initialized with four different land surface conditions. This suite of initial conditions are designed to capture a range of realistic snow configurations for the region and time period. They represent conditions that could have conceivably occurred, but did not necessarily occur, leading up the March 1998 AR in Idaho's northern Rockies. The initial land surface conditions are derived from a 30-yr regional climate run over the same region with the same grid configuration (Flores et al. 2016).

Since the thermodynamic and hydraulic state of the subsurface (soil temperature and soil moisture) coevolve with snowpack, we performed an offline (land surface model only) spinup for one and a half months prior to the AR arrival. We created four end-members: High Initial Snow (HIS), Medium Snow (MIS), Low Snow (LIS), and No Snow (NIS) states by starting the spinup with four unique SWE and SCA configurations. Meteorological forcings used in the offline spinup came from a WRF run (the same for each spinup) over the same time period. In this way, the spinup procedure produces initial land surface states in quasi-equilibrium with both the artificially introduced snow and the atmosphere.

The initial conditions reflect a wide range of snow configurations (Fig. 2). The CFSR has a high SCA but a low SWE. The HIS has a high SWE and a higher SCA than MIS, LIS, and NIS (but not CFSR). The MIS has a higher SWE, but very close to the same starting SCA, as the LIS. The NIS case has no snow
TABLE 1. Weather Research and Forecasting (WRF) Model parameters used in this study.

\begin{tabular}{lc}
\hline \hline \multicolumn{1}{c}{ Parameter } & Value \\
\hline Version & 3.8 .1 \\
Domains & 1,2 \\
Vertical levels & 50,50 \\
W-E dimension & 340,349 \\
N-S dimension & 290,328 \\
$D X$ & $3,1 \mathrm{~km}$ \\
$D Y$ & $3,1 \mathrm{~km}$ \\
Output time step & Hourly \\
Model physics & Option \\
\hline
\end{tabular}

Lateral boundary conditions

Climate Forecast System

Reanalysis (CFSR)

Convection parameterization

Turned off

Microphysics

Thompson

LSM

Noah-MP

Surface layer

Monin-Obukhov (option 2)

PBL

Mellor-Yamada-Janjić

(Eta/NMM) PBL

$\mathrm{LW}$ radiation

SW radiation

Community Atmosphere Model

Community Atmosphere Model

(SWE or SCA), save for one small region to the north of the Boise River basin.

\section{c. Energy budget framework}

We employ a tropospheric energy budget approach to quantify energy exchanges between the land surface and the atmosphere. The energy content of a given column of the atmosphere is the sum of its sensible, latent, kinetic, and potential energy [Eq. (1)], integrated throughout the entire column (from the top of atmosphere with pressure $P_{\text {TOP }}$ to the surface with pressure $\left.P_{\mathrm{SFC}}\right)$ :

$$
E=\frac{1}{g} \int_{P_{\mathrm{TOP}}}^{P_{\mathrm{SFC}}}\left(c_{p} T+L_{v} Q+\Phi+k\right) d p .
$$

In Eq. (1), $c_{p}$ is the specific heat capacity of air at constant pressure (joules per kelvin per kilogram), $T$ is the temperature in kelvins, $L_{v}$ is the latent heat of vaporization of water (joules per kilogram), $Q$ is the specific humidity (kilogram water vapor per kilogram of dry air), $\Phi$ is the geopotential height (joules per kilogram), and $k$ (joules per kilogram) is the kinetic energy. Integrating with respect to a pressure and dividing by gravitational acceleration yields units of joules per meter squared, and differentiating with respect to time yields units of watts per meter squared. The kinetic energy $k$ is much smaller than the other terms. This can be shown by considering some unit density of the atmosphere with homogeneous temperature, moisture content, and a uniform wind speed and noting that the kinetic energy is proportional to the square of the wind speed. Choosing a typical temperature, specific humidity, and wind speed will show that the kinetic energy is $<1 \%$ of the other terms, even for extreme wind speeds. Consequently the kinetic energy term has been omitted from this calculation, as it was in Letcher and Minder (2015) and Porter et al. (2011). 

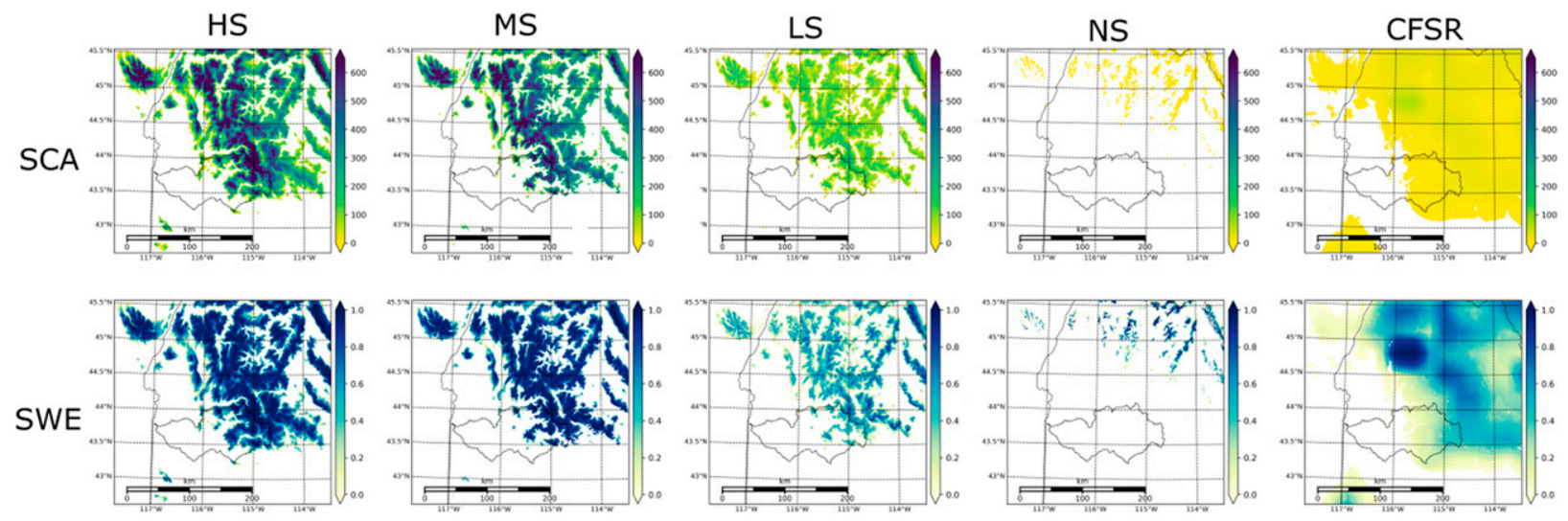

FIG. 2. The initial snow conditions after the spinup period for each different model experiment, HS, MS, LS, NS, and CFSR, for (top) SWE and (bottom) fractional SCA.

We can likewise define the horizontal energy transport field F [Eq. (2)]

$$
\mathbf{F}=\frac{1}{g} \int_{P_{\mathrm{TOP}}}^{P_{\mathrm{SFC}}}\left(c_{p} T+L_{v} Q+\Phi+k\right) \mathbf{V} d p,
$$

where $\mathbf{V}$ is the horizontal wind vector.

The rate of internal energy storage $d E / d t$ must balance the net energy flux at the top of atmospheric column $\left[F_{\mathrm{TOA}}\right.$, Eq. (4)], the net energy flux from the land surface $\left[F_{\mathrm{SFC}}\right.$, Eq. (7)], and the divergence of the horizontal energy transport field. For convenience and following Porter et al. (2011), we denote the convergence of the horizontal energy transport as $F_{\mathrm{WALL}}=-\nabla \cdot \mathbf{F}$.

The top-of-atmosphere flux is the sum of the net longwave $\left(\mathrm{LW}_{\mathrm{TOA}}\right)$ and shortwave $\left(\mathrm{SW}_{\mathrm{TOA}}\right)$ radiation at the top of the column [Eq. (4)]. The arrows denote the direction of the flux (downward is directed toward the land surface), and the uppercase subscript indicates the net flux:

$$
\begin{aligned}
F_{\mathrm{TOA}} & =\mathrm{SW}_{\text {toa } \downarrow}+\mathrm{LW}_{\text {toa } \downarrow}-\left(\mathrm{SW}_{\text {toa } \uparrow}+\mathrm{LW}_{\text {toa } \uparrow}\right) \\
& =\mathrm{SW}_{\mathrm{TOA}}+\mathrm{LW}_{\mathrm{TOA}} .
\end{aligned}
$$

The surface energy flux is the likewise the sum of the shortwave and longwave radiation fluxes in addition to the turbulent fluxes of sensible and latent heat [Eq. (7)]:

$$
\begin{aligned}
F_{\mathrm{SFC}} & =\mathrm{SW}_{\mathrm{sfc} \uparrow}+\mathrm{LW}_{\mathrm{sfc} \uparrow}-\left(\mathrm{SW}_{\mathrm{sfc} \downarrow}+\mathrm{LW}_{\mathrm{sfc} \downarrow}\right)+\mathrm{SH}+\mathrm{LE} \\
& =\mathrm{LW}_{\mathrm{SFC}}+\mathrm{SW}_{\mathrm{SFC}}+\mathrm{SH}+\mathrm{LE} \\
& =\mathrm{RAD}_{\mathrm{SFC}}+\mathrm{SH}+\mathrm{LE} .
\end{aligned}
$$

We also use, later on, the notation $\mathrm{RAD}_{\mathrm{SFC} \downarrow}$ to denote the down welling component of the surface radiation flux.

Together, Eqs. (2)-(4) satisfy

$$
\frac{d E}{d t}=F_{\mathrm{TOA}}+F_{\mathrm{SFC}}+F_{\mathrm{WALL}} .
$$

A convergence of atmospheric energy (positive $F_{\mathrm{WALL}}$ ) means that the column is a sink in the horizontal energy transport field, and the opposite sign means the column is an energy source. A positive $F_{\text {WALL }}$ could represent the advection of sensible heat into a region of melting snow, for example. For simplicity and consistency, all terms of the equation use a sign convention such that positive values represent a flux of energy into the atmospheric column, and negative values indicate flux out of the column (whether through the top, bottom, or "walls"). It is worth noting that this is the opposite of the sign convention used in hydrologic literature for the turbulent and radiative fluxes at the land surface. Specifically, a positive value of $\mathrm{SH}$ or $\mathrm{LH}$ indicates that the atmosphere is heated by the land surface, and a positive $F_{\text {TOA }}$ indicates that there is a net positive incoming radiation at the top of atmosphere.

We calculate the surface fluxes, column integrated energy storage, and top-of-atmosphere fluxes from standard hourly WRF output variables. We calculate $F_{\text {WALL }}$ by differencing from the other terms in Eq. (1). Consequently, there is a possibly significant residual value included in this calculation, since the WRF energy balance does not perfectly close with hourly output (Porter et al. 2011).

In an attempt to isolate the effect of the clouds on the overall energy budget response, we can define the cloud radiative forcing. We expect that there is some chaotic variability caused by any perturbation to initial conditions, and that this variability will manifest through changes in cloud cover and thus top-of-atmosphere radiation flux. The cloud radiative forcing is the ratio difference between the net top of atmospheric radiation and the net "clear sky" top of atmospheric radiation [Eq. (9)]:

$$
\mathrm{CRF}=\mathrm{SW}_{\mathrm{TOA}}+\mathrm{LW}_{\mathrm{TOA}}-\left(\mathrm{SW}_{\mathrm{TOA}, \mathrm{Clear}}+\mathrm{LW}_{\mathrm{TOA}, \mathrm{Clear}}\right) .
$$

A negative value of cloud radiative forcing (CRF) means that clouds are acting to cool the atmospheric column. The clear sky radiation component of the radiation terms are part of WRF standard output.

\section{ROLE OF SNOW IN THE ATMOSPHERIC ENERGY BUDGET}

Snow operates on the atmospheric energy budget described above through two primary pathways. The snow albedo is 

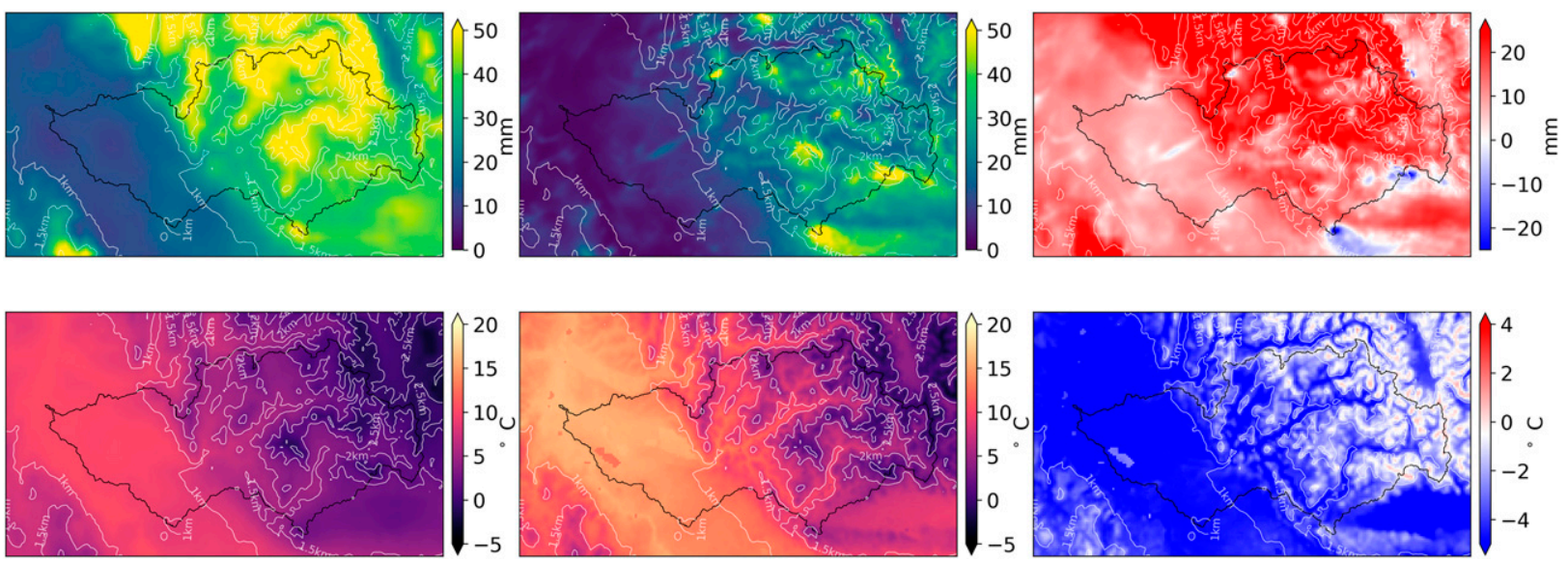

FIG. 3. WRF compared with PRISM for the March 1998 AR event across the Boise River basin. (top) Precipitation and (bottom) mean temperature for (left) PRISM, (center) WRF, and (right) PRISM-WRF.

defined by fraction of shortwave radiation reflected by the surface [Eq. (10)]:

$$
\mathrm{SW}_{\mathrm{SFC}}=\mathrm{SW}_{\mathrm{sfc}, \uparrow}-\mathrm{SW}_{\mathrm{sfc}, \downarrow}=\mathrm{SW}_{\mathrm{sfc}, \downarrow}(1-\alpha) \text {. }
$$

In WRF/Noah-MP, the gridcell albedo $\alpha$ depends on the fractional area of snow in the grid cell and the snow albedo itself, which depends on the snow age. Increasing the areal coverage of snow in the initial conditions leads to a higher domain-wide albedo. The shortwave top-of-atmosphere flux $\mathrm{SW}_{\mathrm{TOA}}$ is impacted by the surface albedo during clear sky conditions, but less when clouds are significant.

Snowmelt acts as an energy sink in the energy budget framework. Melting occurs once the snow warms to its melting temperature and sufficient energy is added to overcome the latent heat of fusion. The latent heat requirement for melt is much larger than the energy required to warm the snowpack:

$$
F_{\mathrm{SFC}}+G=l_{v} M-\frac{d}{d t} \int_{z}^{H_{s}}\left[\rho_{s}(z) c_{p} T_{s}(z)\right] d z,
$$

where $G$ is the ground heat flux in Eq. (11), $l_{v}$ is the latent heat of fusion, $M$ is the melt rate, and the right-hand integral is the total internal energy of the snowpack, integrated from the surface to the top $\left(H_{s}\right)$, with density $\rho_{s}$, and temperature $T$.

Consequently, changes in initial SCA influence the albedo, and changes in initial SWE will influence the size of the snowmelt surface energy sink.

\section{d. Offline snowmelt modeling experimental setup}

In the final segment, we apply the meteorological forcings created from the coupled experiments (described in section 3b) to run an offline (without feedback to the atmosphere) land surface model for the AR event. We use the same initial hydrologic state for each case and examine the final SWE value that results. We again use Noah-MP for consistency with the coupled experiments, but any other distributed energy balance model could have been selected. This is an analogous setup used in some operational practices, where the meteorological outputs from a dynamically downscaled forecast or reanalysis are used to run offline snowmelt or runoff models for water management purposes (e.g., Havens et al. 2019; Zhao et al. 2009). The specific forcing variables used to run are downwelling longwave and shortwave radiation, 2-m air temperature, 2-m specific humidity, surface pressure, meridional and zonal wind at $10 \mathrm{~m}$, and precipitation.

Like the coupled experiments outlined above, the purpose of this experiment is to test the extent to which surface snow processes interact with the atmosphere. If the snow exerts no influence on the atmosphere, then the time series of SWE in the offline experiments should be very similar regardless which set of forcings (HS, NS, etc.) is applied, notwithstanding random changes caused by the weather model's chaotic sensitivity to initial conditions. To further isolate the near-surface atmospheric interactions, we run two experiments: "PFix," where the precipitation is the same across all forcing scenarios, and "RadFix," where the shortwave and longwave, in addition to precipitation, are fixed across all forcing scenarios.

\section{Results}

\section{a. The baseline WRF simulation}

Before examining the results of the snow initialization experiments, we examine the WRF simulated precipitation and temperature during the AR event. Over the 3-day period, the Boise River basin received up to $2.0 \mathrm{~cm}$ of precipitation in some locations, falling as a mixture of rain and snow. The greatest precipitation rates are observed at the highest elevations with high wind speeds. Temperatures are surprisingly warm, with some low elevations upward of $15^{\circ} \mathrm{C}$. Figure 3 examines the differences between WRF and the PRISM climate dataset (Daly et al. 1997). The original 4$\mathrm{km}$ PRISM pixels have been interpolated to the 1-km WRF grid resolution. We stress that this comparison does not 

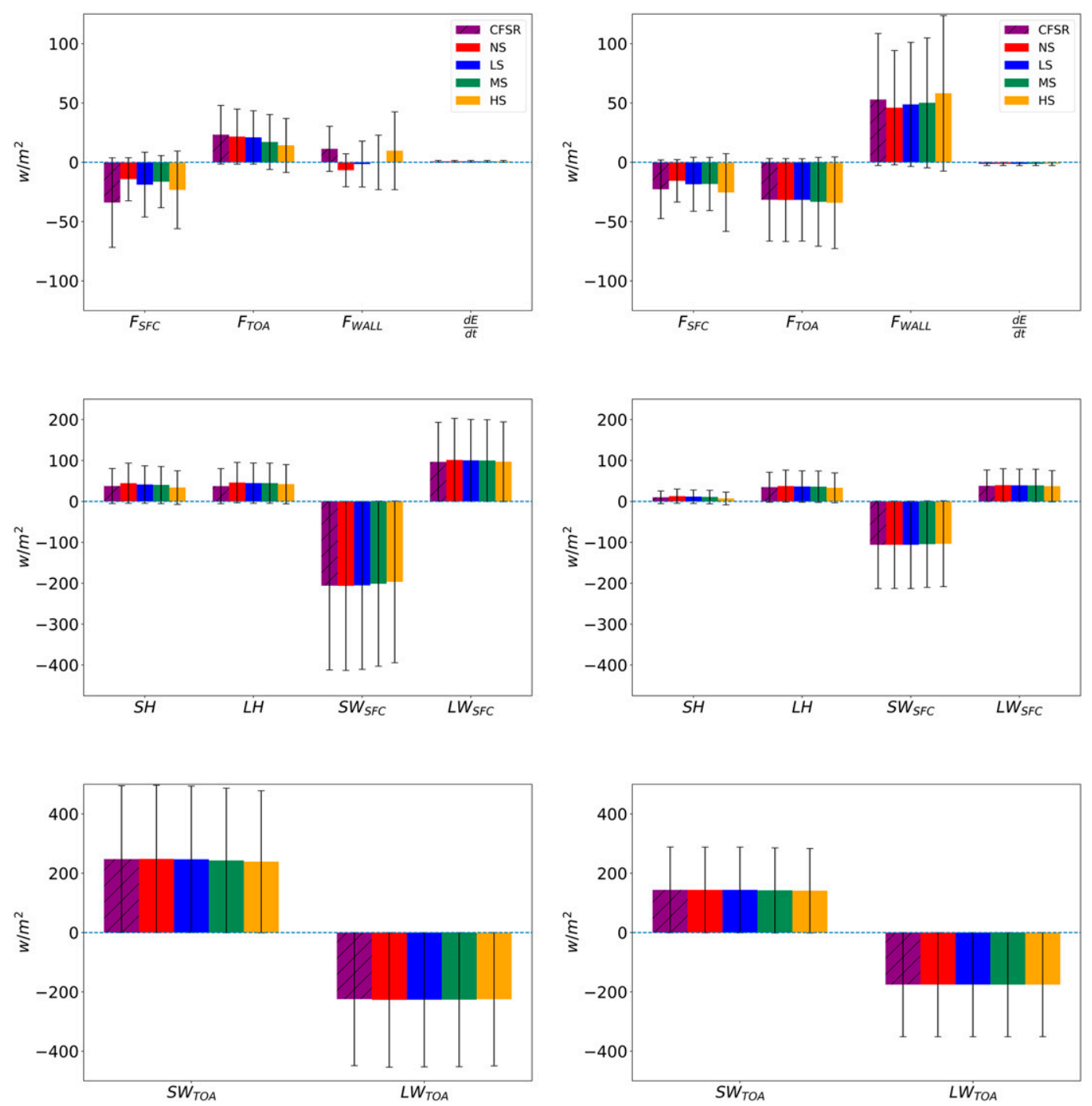

FIG. 4. The Boise River basin averaged energy budget components for the (left) clear sky period and (right) AR period.

constitute a complete validation or verification of this WRF configuration, and that PRISM is itself an estimation of the true meteorological conditions during this time period, based on limited observational information. describes several of the challenges of observing and estimating precipitation in complex terrain. In general, WRF has a patchier, much less persistent precipitation field and warmer valley temperatures by several degrees.

\section{b. Coupled experiments}

We consider the Medium Snow (MS) model scenario the "reference" scenario, and difference the others (HS, LS, NS, CFSR) by the reference (i.e., HS - MS) to show the effect of perturbing the system with the addition/loss of initial snow. We denote the difference by the $\Delta$ symbol. We subdivide the analysis into two periods; the "clear sky" period in the 3 days leading up the AR event, and the
"AR" period during the atmospheric river itself. Each lasts approximately $72 \mathrm{~h}$.

\section{1) THE DOMAIN AVERAGE ATMOSPHERIC ENERGY BUDGET}

The differences between the clear sky and AR period energy regimes are illustrated in Fig. 4, which shows the average flux in the Boise River basin for each component of the energy balance during both clear and cloudy time periods. As expected, the signs of $F_{\text {TOA }}$ reverse (from positive to negative) in the transition to the AR period. Clouds are highly reflective, so $\mathrm{SW}_{\text {TOA }}$ reduces during the AR. There are notable differences between the experiments, especially during the clear sky case. Larger snow-covered areas cause decreases in the top-ofatmosphere shortwave flux. These differences are more pronounced during the clear sky time period, since clouds do not mask the snow albedo. 

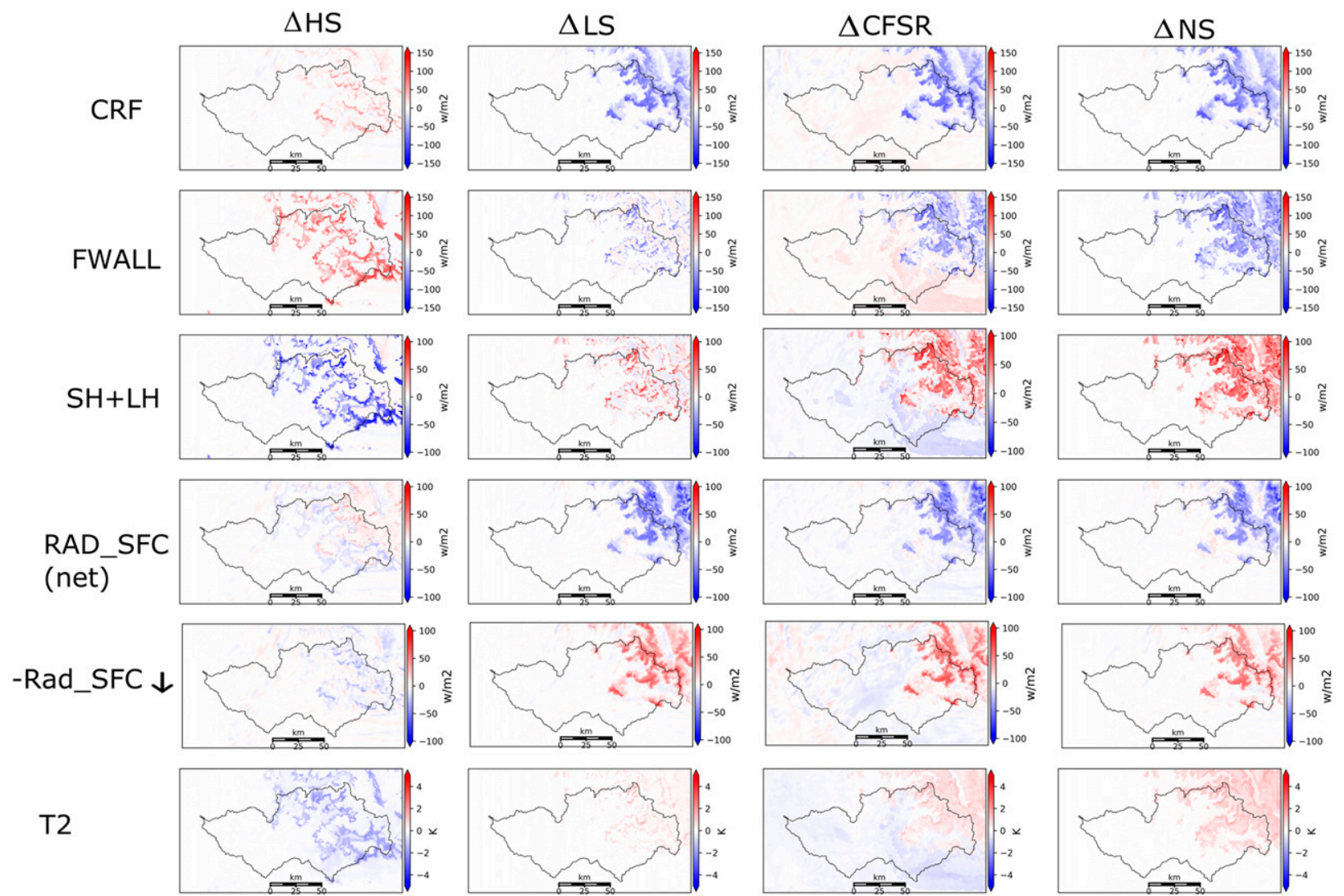

FIG. 5. Map views of $\Delta \mathrm{CRF}, F_{\mathrm{WALL}}, \mathrm{SH}+\mathrm{LH}$, net $\mathrm{RAD}_{\mathrm{SFC}}$, the downwelling component of the surface radiation $\mathrm{RAD}_{\mathrm{SFC}} \downarrow$, and $T^{2 \mathrm{~m}}$ for the AR period.

The sensible heat term shows interesting patterns. SH decreases during the AR period, likely because the intruding air mass is relatively warm, so the temperature gradient between the land surface and atmosphere is lessened and atmospheric heating reduces (recalling, again, that positive values of $\mathrm{SH}$ indicate energy directed into the atmosphere). The $F_{\text {WALL }}$ is greater, for all cases, during the atmospheric river relative to the clear sky state. This is caused by the influx of the warm and moist AR air mass (and hence the moist static energy). The $F_{\text {WALL }}$ is greatest for the HIS case during the AR time period, and greatest for the CFSR case during the clear sky time period. The atmospheric energy storage flux term $(d E / d T)$ is small relative to the other terms.

\section{2) GEOGRAPHIC PATTERNS OF SNOW-ATMOSPHERE INTERACTION}

We can view the differences between the model scenarios and the reference state $(\Delta)$ in map view to discern geographic patterns (Fig. 5) of energy fluxes during the AR period. The maps reveal the regions where snow atmosphere interactions are most active within the Boise River watershed.

Relative to the MS case, the average $T^{2 \mathrm{~m}}$ during the AR period decreases by as much as $4 \mathrm{~K}$ for the cases with HS case, and is several degrees higher in the cases with less initial snow (LS, CFSR, and NS). In the HS case, the largest temperature changes occur in the mid elevations where there is a large difference in the initial snowpack conditions (Fig. 2).

The CRF and downwelling surface radiation plots ( $\left.\operatorname{RAD}_{\mathrm{SFC}} \downarrow\right)$ show the role of clouds on the radiation budget, and that there are significant changes between the different scenarios. The differences in these quantities are equivalent but opposite in sign, and reflect the degree to which changes in cloud cover impact the radiative fluxes. The HS case is generally less cloudy (more downwelling shortwave radiation) than the MS case, whereas the CFSR, LS, and NS are more cloudy (less downwelling shortwave). Comparing these plots with the net surface radiation is complicated by the fact that both the surface albedo (due to snow cover) and downwelling radiation are changing in each experiment.

\section{3) Correlations BetweEn MELTing SNOW AND ENERGY FLUXES}

Figure 6 shows the relationships between 2-m surface air temperature and atmospheric energy transport, surface turbulent exchanges, clear sky radiation flux, and snowmelt during the AR period. We have applied a linear regression for each of the scatterplots. A linear model is generally a poor fit of the data, but in each case we can confidently reject the null hypothesis of a zero-slope relationship between the temperature and the respective variable. While not accounting for 

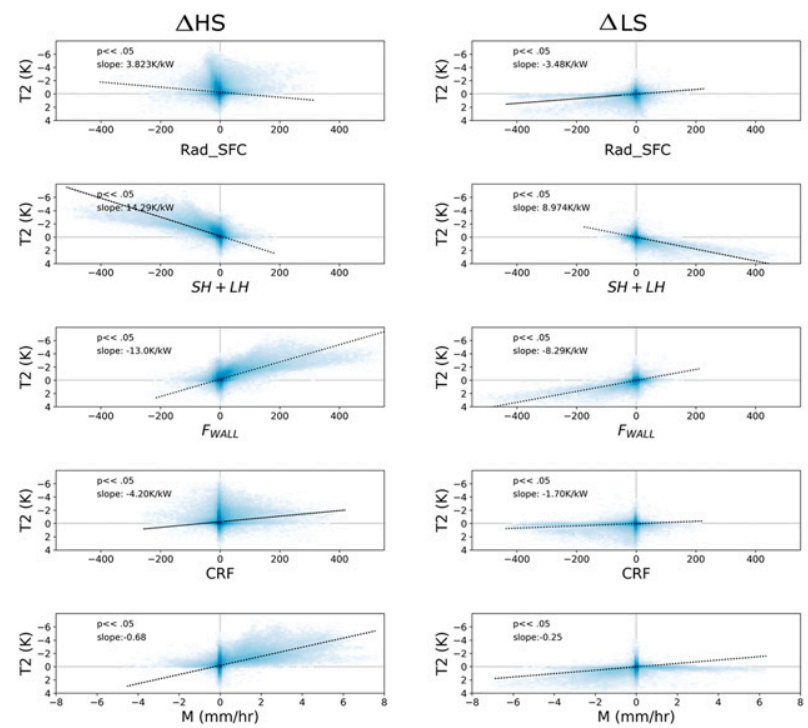
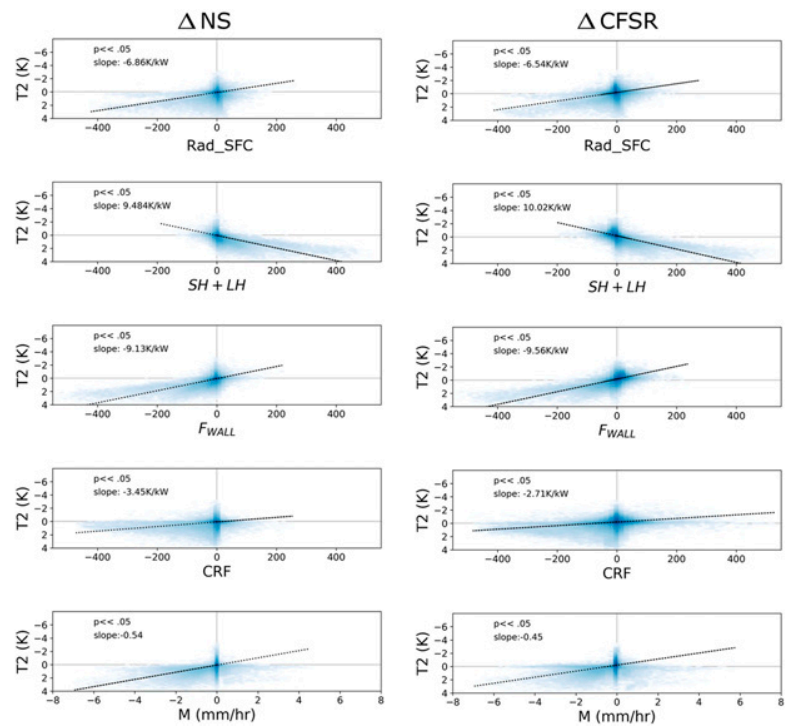

FIG. 6. Scatterplots of $\Delta$ energy flux components during the AR period. From left to right: $\Delta$ HS, LS, NS, and CFSR. The rows (from top to bottom) are the change in the net surface radiation $\mathrm{RAD}_{\mathrm{SFC}}$, turbulent fluxes $\mathrm{SH}+\mathrm{LH}, F_{\mathrm{WALL}}$, CRF, and snowmelt $M$.

confounding variables, the magnitude and direction of the slope provides some means of measuring the sensitivity between each variable pair.

The experiments show that the initial SWE content, acting via the melt-energy sink mechanism, is an important mechanism controlling temperatures, in addition to SCA which acts on the surface radiation balance. We see again that $T^{2 \mathrm{~m}}$ reduces/increases by as much as $4 \mathrm{~K}$ between the cases (relative to the MS) for some time periods during the AR. Perhaps counterintuitively, reductions in $T^{2 \mathrm{~m}}$ correspond with areas of increased snowmelt. Here, the latent heat lost to the melting snow reduces the air temperature. This process would not be captured by an uncoupled land surface model (which does not feedback to the atmospheric forcings), where one would expect additional melt to be caused by an increase in temperature. The temperature-melt relationship changes for the LS, NS, and CFSR scenarios. Here, reduced rates of melt correspond with increased temperatures. Some of these grid cells have a zero initial snow coverage, whereas the companion MS grid cell have a nonzero initial snow. Warmer temperatures in these experiments correspond with regions of positive sensible and latent heat flux, meaning that the less-snowy regions warm/evaporate and provide sensible/latent heat to the atmosphere. It is worth noting that there are some grid cells and time steps during the AR in which the NS case has a greater rate of melt $(M)$ than the MS case. This is possible because there is still snowfall during the AR event, some of which melts.

The relationships between $\mathrm{RAD}_{\mathrm{SFC}}$ and $\mathrm{CRF}$ have relatively weaker relationship with temperature compared to the other variables. This suggests that the changes in the radiative forcing caused by changes in cloud cover are not the key driver of the changes in temperature, but rather the changes in temperature are associated with surface snow changes. If temperature changes were caused by changes in the CRF, then we would expect a more linear relationship. Examining the HS experiment shows that the peak of the temperature-CRF plot is centered approximately at zero, where there is no change in CRF.

For both the clear (not shown) and AR periods, reductions in the surface temperatures (whatever the cause) lead to increases in the convergence of the energy transport field $\left(\Delta F_{\mathrm{WALL}}\right)$. Through this mechanism, the atmosphere acts to dampen temperature perturbations caused by the presence of reflective and/or melting snow. The energy transport can come from other regions, or from the model boundaries. In a large domain, we might expect this mechanism to lead to a more widespread cooling signal throughout the region, even over areas where there was no change in the snowpack initial conditions, but it is not apparent for this small domain.

\section{4) Summary OF THE COUPLED EXPERIMENTS}

To summarize, as the warm atmospheric river air mass enters the watershed and begins to exchange energy with the land surface, snow acts as a "buffer" against the change in the land surface temperature, especially as it melts. These areas of melting snow reduce sensible heating from the land surface. There are significant differences in the cloud radiative forcing and subsequent surface down welling radiation among the experiments, but these changes have a lesser impact on surface temperatures than the snow surface changes. The snow-latent heat sink mechanism (controlled by SWE) is more significant than the snow-albedo feedback (controlled by SCA) in controlling temperatures. These processes establish a thermal gradient in the lower troposphere that leads to an increase in the advection of moist static energy into snow regions.

\section{c. Offline experiments}

In this section we run the "offline" Noah-MP model with the MS snow initial state forced by the time series of meteorological conditions created from the four experiments in the previous 

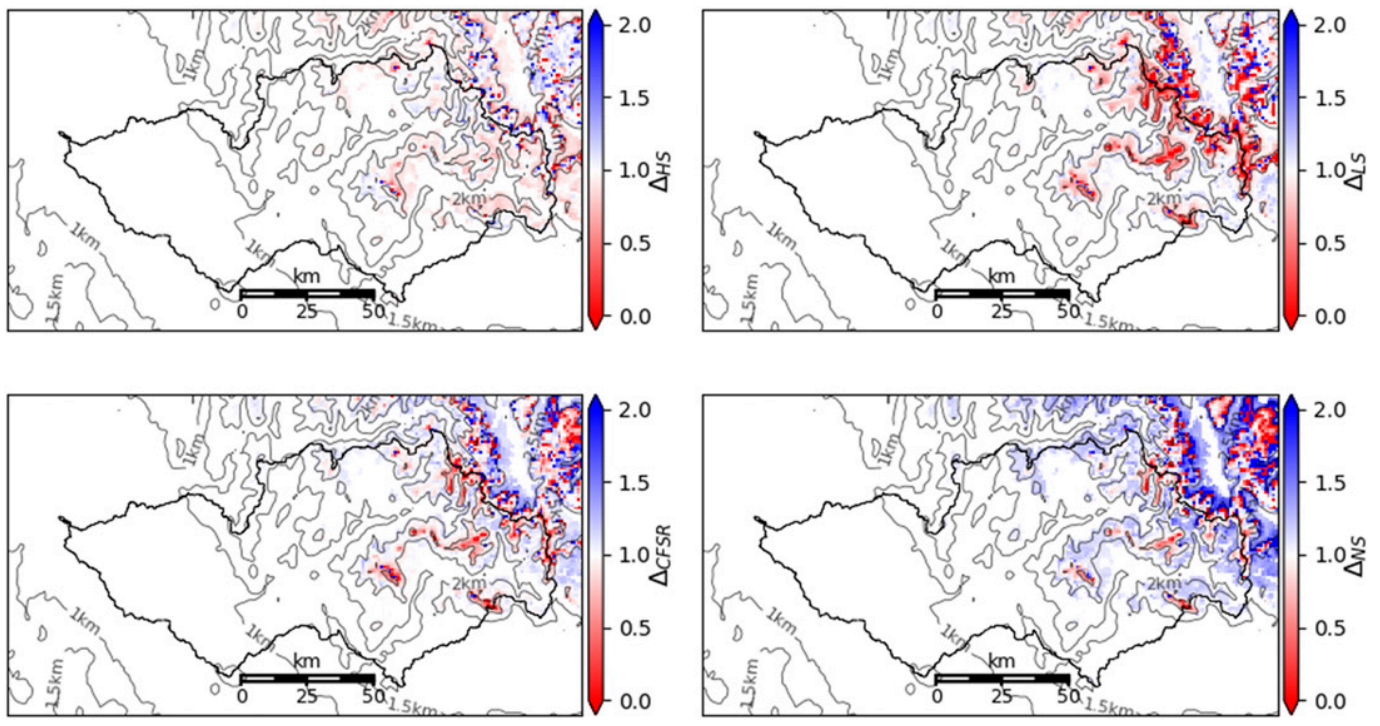

FIG. 7. The PFix experiment, showing the ratio of SWE change in the HS, LS, NS, and CFSR experiments relative to the MS forced case. A value of 1 is no change in the final SWE.

section. In this way, we can isolate the effects of the landatmosphere interactions on the evolution of SWE. This experiment is analogous to operational practices where NWP models are used to run offline snowmelt or hydrologic models without feedback into atmospheric processes. We choose the MS snow state as the reference initial land surface condition in absence of a better analysis. The PFix and RadFix experiments (described in section 3) fix the precipitation, and precipitation in addition to radiation forcings, respectively, with the forcings from the MS scenario.

We compare SWE between the model runs at the final time step of the offline model run. The difference (denoted $\Delta$ ) is caused by some combination of melt and accumulation from precipitation. To compare across scenarios, we compute the ratio of $\triangle \mathrm{SWE}$ between each run and the reference MS case [Eq. (12)], recalling that the initial SWE value is the same for all of the experiments:

$$
\Delta_{i}=\frac{\Delta \mathrm{SWE}_{i}}{\Delta \mathrm{SWE}_{\mathrm{MS}}}=\frac{\mathrm{SWE}_{\mathrm{Final}, i}}{\mathrm{SWE}_{\mathrm{Final}, \mathrm{MS}}}
$$

where $i$ is a snow condition member (HS, LS, NS, or CFSR). A value of $\Delta_{i}=2$ indicates the experiment has twice the final SWE of the reference, a value of 1 indicates no change, etc.

\section{1) PFIX OFFLINE RUN}

In this experiment, the precipitation forcings are consistent across all experiments. There are significant differences in SWE caused by the differences in nonprecipitation forcings alone (Fig. 7). The primary change in SWE is via melting, so the differences in Fig. 7 indicate different rates of melt averaged across the entire model domain (extending beyond the Boise River basin), the low-snow forcings (hereafter CFSR, LS, NS) yield a greater rate of melt than the MS forcings for areas in lower elevations (positive regions), while the HS forcings yield a lesser rate of melt. This is especially evident in the mountain peaks in the western region of the watershed and in the prominent river valley to the north of the watershed. The patterns of SWE change do not perfectly match the maps of temperature difference. The changes in the radiative forcing caused by cloud changes has a significant impact of the ratios of SWE change, as the next section demonstrates.

\section{2) RADFIX OFFLINE RUN}

In this experiment, the precipitation in addition to shortwave and longwave forcings are consistent across all experiments, but all other forcings are allowed to vary. Figure 8 shows a more consistent pattern of snowmelt ratios than the PFix case. The HS forced case has significantly reduced rates of melt relative to the MS, whereas the NS, LS, and CFSR forced cases have much higher rates of melt. There is a clear relationship between elevation and the melt rate ratio, whereby the highest elevations have the largest departures from the reference scenario (Fig. 9). This in part reflects the initial distribution of SWE, since there is more available for melting at high elevations.

\section{Discussion}

The range of initial snow conditions presented in this paper is conservative. Snow depth and snow cover have a large annual and interannual variability across the mountains of the western United States, associated with both large-scale circulation patterns (Cayan 1996), the incidence of large AR events (Guan et al. 2010), and variability imposed by local land surface processes such as wind redistribution and vegetation interception. Consequently, the number of snow end-members presented here is not completely representative of the possible snow states for this region.

It is important to recognize that the gridcell albedo in Noah-MP is controlled by 1) snow albedo decay functions 2) 

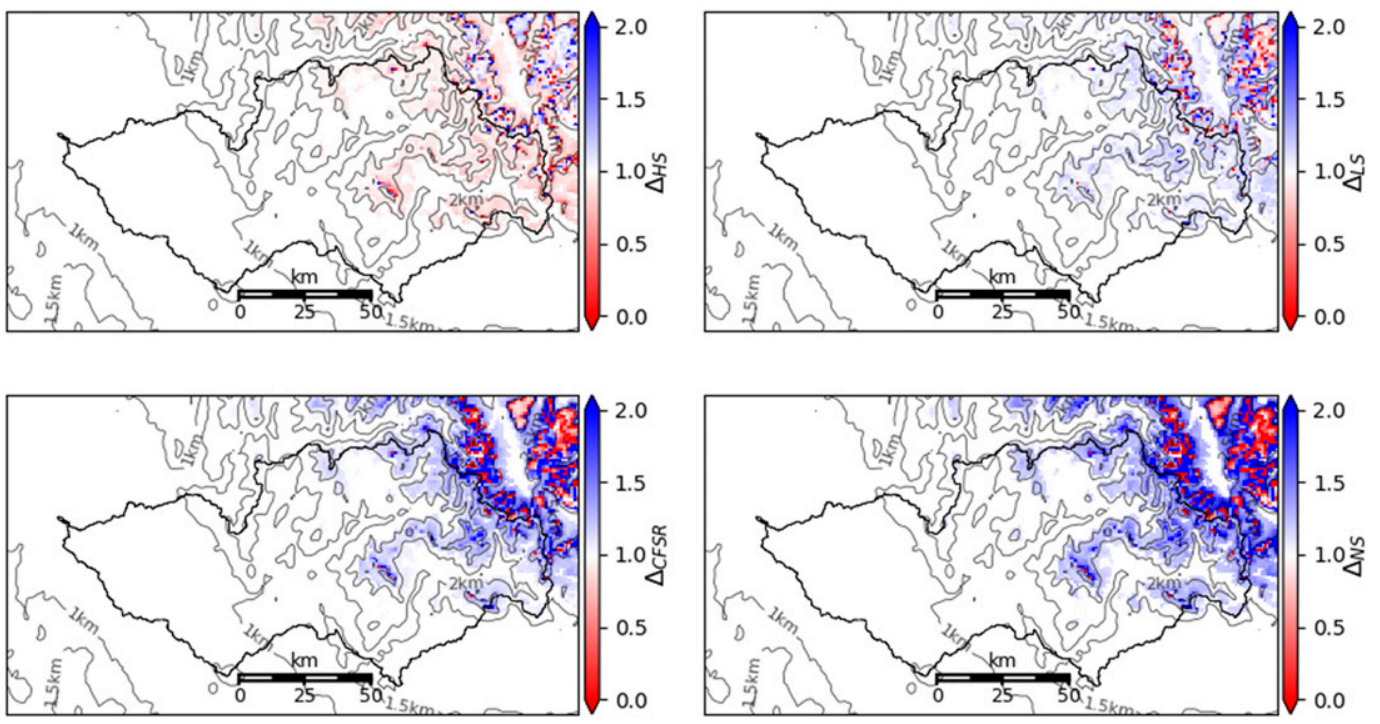

FIG. 8. The RadFix experiment, showing the ratio of SWE change in the HS, LS, NS, and CFSR experiments relative to the MS forced case. A value of 1 is no change in the final SWE.

empirical snow-depletion curves relating gridscale snow-covered area to the SWE from the energy and mass balance model. In this way, the duration and magnitude of the snow albedo feedback depends on (and also influences) the dynamics of snowmelt and accumulation. This also means that in this experimental setup, we cannot completely disentangle the relative effects of SCA/SWE on land-atmosphere interactions since they do not evolve independently.

The model resolution and physics options may influence the results, particular as they influence boundary layer processes. Parameterizing the turbulent fluxes within the boundary and surface layers is a vexing problem (Prein et al. 2015), since finescale flow features are not resolved by the model. For this study, we used the Eta surface layer (Janjić 1994) and Mellor-Yamada-Janjić planetary boundary layer physics scheme (Table 1). Consequently the vertical resolution of the lowest model layers may impact model outputs such as wind, specific humidity, and temperature at the reference heights. Mott et al. (2015) used a large-eddy simulation to examine the local scale advection of sensible heat over snow patches for both ambient and windy conditions. They concluded that highly "patchy" snow covers created thermal heterogeneities that lead to advection of sensible heat from bare to snowy areas, and that this process is amplified by synoptic winds for $5-\mathrm{m}$ large-eddy simulations, but not for coarser-resolution simulations with fewer vertical levels. These finescale boundary layer features are not captured in our model resolution.

We demonstrate there are important local interactions between melting snow, $T^{2 \mathrm{~m}}$, and atmospheric energy transport at regional scales, mostly independent of the snow-albedo feedback mechanism (Fig. 5, Fig. 4) that occur even during cloudy periods. This mechanism depends on the magnitude of SWE, since this determines the amount of latent heat lost to melting snow. In a set of WRF pseudoglobal warming scenarios, Letcher and Minder (2015) analyzed the impact of snow feedbacks on regional climate across the Colorado Rockies, and found that snowmelt was an important component of the regional energy balance and responded to increases in atmospheric energy convergence, even in the absence of changes in the top-of-atmosphere radiation flux. Our results agree with this finding, as demonstrated by the differences in the energy balance between the LS and NS scenarios (Fig. 6). In our experimental setup, we were able to further isolate this effect, since the boundary conditions for each of the WRF model runs do not change, unlike in pseudoglobal warming experiments where temperature perturbations are added to the model boundary conditions.

Snow's influence on $T^{2 \mathrm{~m}}$ is greatest over areas of melting snow (Fig. 6). This finding agrees with that of Xu and Dirmeyer

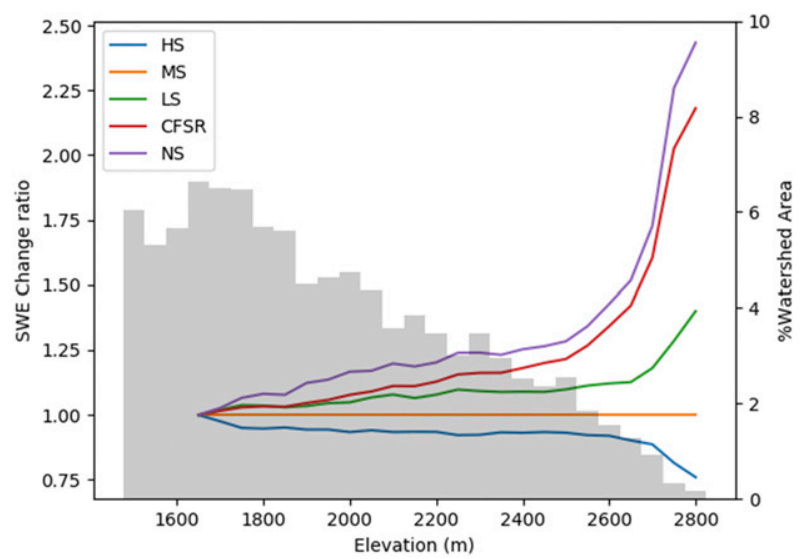

FIG. 9. Elevation vs the ratio of SWE change for the HS, MS, LS, NS, and CFSR experiments relative to the reference MS case. Gray bars show the fraction of the watershed occupied by that elevation band. 
(2011), who investigated snow atmosphere coupling using an ensemble of GCM experiments. They found that a measure of snow-atmosphere coupling was greatest in magnitude during the spring snow melting period. However, it is difficult to compare our findings with those from global model experiments given the different process and time scales resolved. Future research may interrogate snow atmosphere coupling strength at a regional scale over a longer time frame, and apply a coupling strength metric similar to $\mathrm{Xu}$ and Dirmeyer (2011).

Our findings suggests that SWE information, in addition to $\mathrm{SCA}$, is required to reasonably assess local snow-atmosphere couplings. Consequently, we propose that improved snow state retrievals and assimilation practices may be an additional source of hydrometeorological predictability. The most similar operational forecast model to the WRF configuration used here is the NOAA High Resolution Rapid Refresh (HRRR) model (Benjamin et al. 2016). HRRR likewise uses WRF but coupled with the RUC land surface model. HRRR provides hourly updated weather forecasts on an hourly basis. The snow states in HRRR undergo a daily assimilation step via direct insertion of the NOAA/NESDIS snow-covered area product. Snowpack and soil temperatures also are updated using an empirical approach. The next generation of snow remote sensing products may offer significantly improved snow states for assimilation (Kim et al. 2018).

While CFSR is a coarser product not designed to capture watershed-scale heterogeneities, our findings do highlight some of the deficiencies of the CFSR snow reanalysis. CFSR, in addition to the National Centers for Environmental Prediction's Global Forecast System (GFS) and North American Mesoscale Forecast System (NAM), assimilate snow depth data from the Air Force Weather Agency (AFWA) SNODEP product (Kopp 1996), which is based on passive microwave retrievals from satellites. Dawson et al. (2016), Broxton et al. (2016), and Wrzesien et al. (2019) all found considerable low biases for CFSR and other reanalyses products. These insights combined with results from our work suggest that the initial reanalysis states and spinup times should be carefully considered in highresolution weather modeling applications, since snow can impact atmospheric states.

The differences in precipitation and cloud cover are generally small and lack a consistent structure, and are likely more related to the chaotic nature of the atmosphere rather than a consistent mechanism that could be considered a feedback. Using a larger WRF domain with parameterized convection, Leung and Qian (2009) noted that small changes in atmospheric stability, and the Froude number, have a large impact on the distribution of precipitation across the western United States during AR events. Some research has suggested the possible coupling between snow cover and precipitation through a snowfall-stability mechanism (Walland and Simmonds 1996; Xu and Dirmeyer 2011), but given the strong synoptic forcing of the AR event, it is likely not captured here.

While this research demonstrates the potential significance of initial land surface snow states in numerical weather modeling, there are many open questions. To understand the potential ramifications for operational weather forecasting, further investigation is needed to ascertain the extent to which the observed effect is larger than uncertainties in, for instance, initial conditions in the driving atmospheric forcings. Although we would imagine that the effect size would vary depending upon both the magnitude of uncertainties in initial conditions and the forecast lead time, a rigorous uncertainty analysis could help establish under what circumstances improved knowledge of spatial snow cover characteristics would be valuable for weather forecasting.

\section{Conclusions}

We find that representing snow-atmosphere interactions can have significant hydrologic impacts. Consequently, the initial snow states used for numerical weather prediction, dynamical downscaling, or hindcasting should be carefully evaluated, especially in mountainous areas, where reanalyses products grossly underestimate snow mass. Numerical experiments show that horizontal atmospheric energy transport responds to surface energy perturbations caused by snow and redistributes latent and sensible heat energy available for melting (Fig. 6). Differences in initial SWE and SCA impose a control on the 2-m air temperature by $\pm 4 \mathrm{~K}$, even during atmospheric river events. Consequently, we propose that more realistic snow states may be a source of numerical weather prediction skill. This work demonstrates the need for improved SWE remote sensing capabilities and land surface data assimilation platforms for weather models. Further investigations are needed to quantify the specific circumstances and value added of improved snow information for weather forecasts.

Acknowledgments. The authors would the acknowledge funding support from the following sources: NSF CAREER (EAR-1352631), NASA EPSCoR (NNX14AN39A), and NASA Terrestrial Hydrology Program (NNX15AD56G). All data model outputs and codes used are available by request.

\section{REFERENCES}

Alexander, M. A., J. D. Scott, D. Swales, M. Hughes, K. Mahoney, and C. A. Smith, 2015: Moisture pathways into the U.S. Intermountain West associated with heavy winter precipitation events. J. Hydrometeor., 16, 1184-1206, https://doi.org/ 10.1175/JHM-D-14-0139.1.

Baker, D. G., D. L. Ruschy, R. H. Skaggs, and D. B. Wall, 1992: Air temperature and radiation depressions associated with a snow cover. J. Appl. Meteor., 31, 247-254, https://doi.org/10.1175/ 1520-0450(1992)031<0247:ATARDA > 2.0.CO;2.

Bamzai, A. S., and J. Shukla, 1999: Relation between Eurasian snow cover, snow depth, and the Indian summer monsoon: An observational study. J. Climate, 12, 3117-3132, https://doi.org/ 10.1175/1520-0442(1999)012<3117:RBESCS>2.0.CO;2.

Benjamin, S. G., and Coauthors, 2016: A North American hourly assimilation and model forecast cycle: The rapid refresh. Mon. Wea. Rev., 144, 1669-1694, https://doi.org/10.1175/MWR-D-15-0242.1.

Broxton, P. D., X. Zeng, and N. Dawson, 2016: Why do global reanalyses and land data assimilation products underestimate snow water equivalent? J. Hydrometeor., 17, 2743-2761, https://doi.org/10.1175/JHM-D-16-0056.1.

Cayan, D. R., 1996: Interannual climate variability and snowpack in the western United States. J. Climate, 9, 928-948, 
https://doi.org/10.1175/1520-0442(1996)009<0928:ICVASI > 2.0.CO;2.

Cohen, J., 1994: Snow cover and climate. Weather, 49, 150-156, https://doi.org/10.1002/j.1477-8696.1994.tb05997.x.

Daly, C., G. Taylor, and W. Gibson, 1997: The prism approach to mapping precipitation and temperature. Proc. 10th Conf. on Applied Climatology, Reno, NV, Amer. Meteor. Soc., 20-23.

Dawson, N., P. Broxton, X. Zeng, M. Leuthold, M. Barlage, and P. Holbrook, 2016: An evaluation of snow initializations in NCEP global and regional forecasting models. J. Hydrometeor., 17, 1885-1901, https://doi.org/10.1175/ JHM-D-15-0227.1.

Ellis, A. W., and D. J. Leathers, 1999: Analysis of cold airmass temperature modification across the U.S. Great Plains as a consequence of snow depth and albedo. J. Appl. Meteor., 38, 696-711, https://doi.org/10.1175/1520-0450(1999)038<0696:AOCATM> 2.0.CO;2.

Flores, A., M. Masarik, and K. Watson, 2016: A 30-year, multi-domain high-resolution climate simulation dataset for the interior Pacific northwest and southern Idaho. Lab for Ecohydrology and Alternative Futuring, Boise State University, accessed 1 May 2018, https://doi.org/10.18122/ B2LEAFD001.

Guan, B., and D. E. Waliser, 2015: Detection of atmospheric rivers: Evaluation and application of an algorithm for global studies. J. Geophys. Res., 120, 12 514-12 535, https://doi.org/10.1002/ $2015 J D 024257$.

— N. P. Molotch, D. E. Waliser, E. J. Fetzer, and P. J. Neiman, 2010: Extreme snowfall events linked to atmospheric rivers and surface air temperature via satellite measurements. Geophys. Res. Lett., 37, L20401, https://doi.org/10.1029/ 2010 GL044696.

Havens, S., D. Marks, K. FitzGerald, M. Masarik, A. N. Flores, P. Kormos, and A. Hedrick, 2019: Approximating input data to a snowmelt model using weather research and forecasting model outputs in lieu of meteorological measurements. J. Hydrometeor., 20, 847-862, https://doi.org/10.1175/JHM-D18-0146.1.

Janjić, Z. I., 1994: The step-mountain eta coordinate model: Further developments of the convection, viscous sublayer, and turbulence closure schemes. Mon. Wea. Rev., 122, 927-945, https://doi.org/10.1175/1520-0493(1994)122<0927:TSMECM> 2.0.CO;2.

Kim, E. J., C. K. Gatebe, D. K. Hall, and D. H. Kang, 2018: NASA's SnowEx campaign and measuring global snow from space. NASA, 36 pp., https://ntrs.nasa.gov/citations/ 20180005187

Kopp, T., 1996: The air force global weather central cloud analysis model. Preprints, 15th Conf. on Weather Analysis and Forecasting, Norfolk, VA, Amer. Meteor. Soc., 220-222.

Letcher, T. W., and J. R. Minder, 2015: Characterization of the simulated regional snow albedo feedback using a regional climate model over complex terrain. J. Climate, 28, 7576-7595, https://doi.org/10.1175/JCLI-D-15-0166.1.

— , and — 2018: The simulated impact of the snow albedo feedback on the large-scale mountain-plain circulation east of the Colorado rocky mountains. J. Atmos. Sci., 75, 755-774, https://doi.org/10.1175/JAS-D-17-0166.1.

Leung, L. R., and Y. Qian, 2009: Atmospheric rivers induced heavy precipitation and flooding in the western U.S. simulated by the WRF regional climate model. Geophys. Res. Lett., 36, L03820, https://doi.org/10.1029/2008GL036445.
Marks, D., J. Kimball, D. Tingey, and T. Link, 1998: The sensitivity of snowmelt processes to climate conditions and forest cover during rain-on-snow: A case study of the 1996 Pacific Northwest flood. Hydrol. Processes, 12, 1569-1587, https://doi.org/10.1002/(SICI)1099-1085(199808/09)12:10/ $11<1569::$ AID-HYP682>3.0.CO;2-L.

Mote, T. L., 2008: On the role of snow cover in depressing air temperature. J. Appl. Meteor. Climatol., 47, 2008-2022, https:// doi.org/10.1175/2007JAMC1823.1.

Mott, R., M. Daniels, and M. Lehning, 2015: Atmospheric flow development and associated changes in turbulent sensible heat flux over a patchy mountain snow cover. J. Hydrometeor., 16, 1315-1340, https://doi.org/10.1175/ JHM-D-14-0036.1.

Neiman, P. J., F. M. Ralph, G. A. Wick, J. D. Lundquist, and M. D. Dettinger, 2008: Meteorological characteristics and overland precipitation impacts of atmospheric rivers affecting the west coast of North America based on eight years of SSM/I satellite observations. J. Hydrometeor., 9, 22-47, https://doi.org/10.1175/ 2007JHM855.1.

_- L. J. Schick, F. M. Ralph, M. Hughes, and G. A. Wick, 2011: Flooding in western Washington: The connection to atmospheric rivers. J. Hydrometeor., 12, 1337-1358, https://doi.org/ 10.1175/2011JHM1358.1.

Niu, G.-Y., and Coauthors, 2011: The community Noah land surface model with multiparameterization options (Noah-MP): 1. Model description and evaluation with local-scale measurements. J. Geophys. Res., 116, D12109, https://doi.org/10.1029/2010JD015139.

Porter, D. F., J. J. Cassano, and M. C. Serreze, 2011: Analysis of the arctic atmospheric energy budget in WRF: A comparison with reanalyses and satellite observations. J. Geophys. Res., 116, D22108, https://doi.org/10.1029/2011JD016622.

Prein, A. F., and Coauthors, 2015: A review on regional convectionpermitting climate modeling: Demonstrations, prospects, and challenges. Rev. Geophys., 53, 323-361, https://doi.org/10.1002/ 2014RG000475.

Ralph, F. M., P. J. Neiman, G. A. Wick, S. I. Gutman, M. D. Dettinger, D. R. Cayan, and A. B. White, 2006: Flooding on California's Russian river: Role of atmospheric rivers. Geophys. Res. Lett., 33, L13801, https://doi.org/10.1029/2006GL026689.

Rutz, J. J., W. J. Steenburgh, and F. M. Ralph, 2015: The inland penetration of atmospheric rivers over western North America: A Lagrangian analysis. Mon. Wea. Rev., 143, 1924-1944, https:// doi.org/10.1175/MWR-D-14-00288.1.

Saha, S., and Coauthors, 2010: The NCEP Climate Forecast System Reanalysis. Bull. Amer. Meteor. Soc., 91, 1015-1058, https:// doi.org/10.1175/2010BAMS3001.1.

Schlögl, S., M. Lehning, and R. Mott, 2018: How are turbulent sensible heat fluxes and snow melt rates affected by a changing snow cover fraction? Front. Earth Sci., 6, 154, https://doi.org/ 10.3389/feart.2018.00154.

Segal, M., J. Garratt, R. Pielke, and Z. Ye, 1991: Scaling and numerical model evaluation of snow-cover effects on the generation and modification of daytime mesoscale circulations. J. Atmos. Sci., 48, 1024-1042, https://doi.org/10.1175/15200469(1991)048<1024:SANMEO > 2.0.CO;2.

Skamarock, W. C., and Coauthors, 2008: A description of the Advanced Research WRF version 3. NCAR Tech. Note NCAR/TN-475+STR, 113 pp., https://doi.org/10.5065/D68S4MVH.

Sobolowski, S., G. Gong, and M. Ting, 2010: Modeled climate state and dynamic responses to anomalous North American snow cover. J. Climate, 23, 785-799, https://doi.org/10.1175/ 2009JCLI3219.1. 
Verseghy, D. L., 1991: CLASS-A Canadian land surface scheme for GCMS. I. Soil model. Int. J. Climatol., 11, 111-133, https:// doi.org/10.1002/joc.3370110202.

Walland, D., and I. Simmonds, 1996: Modelled atmospheric response to changes in northern hemisphere snow cover. Climate Dyn., 13, 25-34, https://doi.org/10.1007/s003820050150.

Weisman, M. L., W. C. Skamarock, and J. B. Klemp, 1997: The resolution dependence of explicitly modeled convective systems. Mon. Wea. Rev., 125, 527-548, https:// doi.org/10.1175/1520-0493(1997)125<0527:TRDOEM> 2.0.CO;2.
Wrzesien, M. L., T. M. Pavelsky, M. T. Durand, J. Dozier, and J. D. Lundquist, 2019: Characterizing biases in mountain snow accumulation from global datasets. Water Resour. Res., 55, 9873-9891, https://doi.org/10.1029/2019WR025350.

Xu, L., and P. Dirmeyer, 2011: Snow-atmosphere coupling strength in a global atmospheric model. Geophys. Res. Lett., 38, L13401, https://doi.org/10.1029/2011GL048049.

Zhao, Q., Z. Liu, B. Ye, Y. Qin, Z. Wei, and S. Fang, 2009: A snowmelt runoff forecasting model coupling WRF and DHSVM. Hydrol. Earth Syst. Sci., 13, 1897-1906, https://doi.org/10.5194/ hess-13-1897-2009. 